\title{
Super Capacitors Monitoring System Using CAN Bus Protocol
}

\author{
Josefina Castañeda-Camacho, Angel Bulmaro-Sánchez, Gerardo Mino-Aguilar, Germán Muñóz, \\ Manuel Tlapa, Daniel Ortiz
}

Electronics Departament, Benemérita Universidad Autónoma de Puebla BUAP, Puebla, México

\section{Email address:}

Josefina.castaneda@correo.buap.mx (J. Castañeda-Camacho), absr25@hotmail.com (A. Bulmaro-Sánchez), gmino44@ieee.org (G. Mino-Aguilar), gmunoz64@yahoo.com.uk (G. Muñóz)

\section{To cite this article:}

Josefina Castañeda-Camacho, Angel Bulmaro-Sánchez, Gerardo Mino-Aguilar, Germán Muñóz, Manuel Tlapa, Daniel Ortiz. Super Capacitors Monitoring System Using CAN Bus Protocol. Journal of Electrical and Electronic Engineering. Vol. 5, No. 4, 2017 , pp. 123-129. doi: $10.11648 /$ j.jeee. 20170504.13

Received: May 18, 2017; Accepted: June 12, 2017; Published: July 18, 2017

\begin{abstract}
The present work describes a monitoring system of a bank of supercapacitors (SCB) based on the use of CAN BUS protocol as the data transmission mode. A boost converter with $12.5 \mathrm{~V}$ at its output is included to stabilize the voltage in the supercapacitors. This paper provide a basis for the design of a diagnostic systems which aim to monitor the storage, to extend the supercapacitors life cycle and to detect the voltage variations outside the range of operation that could damage the bank. A circuit is implemented in a way that it allows to balance the voltages of the SCB and to avoid a variation of voltage that could cause the destruction of the components. The monitoring system will receive the voltage data of the SCB by means of the CAN bus protocol and show these voltages through a graphical interface in an intelligent screen, the monitoring will allow to detect an over voltage and thus avoid premature damage in these elements.
\end{abstract}

Keywords: CD/CD, Converter, Supercapacitor, Balance Circuit, CAN Bus Network

\section{Introduction}

Currently, the use of monitoring and diagnostic systems for different applications has been important because they provide the user with an interface to visualize the operation and to detect possible errors. The essential point for these systems is to show the results in a simple way. Thus, it is important to consider the qualities of them elements as the DC-DC converters that allow from a constant DC source to control the DC voltage at the output of the converter. These converters have multiple applications: power sources in computers, distributed power systems, power systems in electric vehicles, etc., [1] - [28].

There are multiple applications of supercapacitors (SC) in the aerospace, automotive industry, traction systems, etc. Then, it is important to consider that the voltage in a serial to parallel connection of these devices will not be equally distributed and can lead to an asymmetric voltage between them. To avoid this problem, different topologies of voltage balance circuits connected to the SC network are implemented to allow their correct distribution of voltage in each supercapacitor.

The Controller Area Network protocol (CAN, also known as CAN bus) is a serial communication protocol with a bus topology designed to exchange information between multiple electronic control units within a distributed system. The main advantages of this protocol are, the robustness to electromagnetic interference, real time information exchange, transmission of up to 8 bytes per frame, bus topology that considerably reduces wiring, etc. The characteristics of the CAN bus have placed it as a protocol of the automotive and the automation industry.

\section{System Diagram Block}

Figure 1 shows the block diagram of the monitoring system integrated by a boost DC-DC converter that provides the voltage to feed the SCB, a voltage balancing circuit for the SCB and a CAN network consisting of two nodes. CAN 1 acquires the voltages from the balance circuit and DC-DC converter to send them to CAN 2 node. Then, CAN 2 node sends the data by serial communication to the smart screen. 


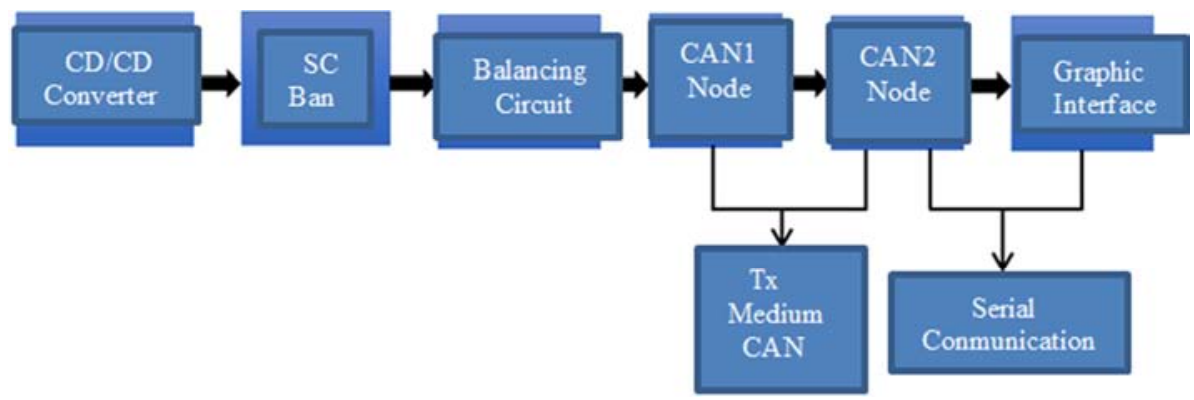

Figure 1. Block diagram of SCB monitoring system.

\subsection{Dc-Dc Converter}

To feed the SCB, it is required a constant power supply of $12.5 \mathrm{~V}$, because of this set is integrated by $5 \mathrm{SC}$ working at a nominal voltage of $2.5 \mathrm{~V}$. Therefore, the system require the design of a Boost converter or elevator that will be a source of constant voltage able to power the SCB. This type of converter is a feasible way of increasing the output voltage, thanks to its high efficiency it is possible to provide the voltage required by the SCB. The design of this converter was made from the basic topology for CD-CD type boost converters. Figure 2 shows the boost converter. The design consists of a DC-DC converter that has a $9 \mathrm{~V}$ voltage input and a $12.5 \mathrm{~V}$ output.

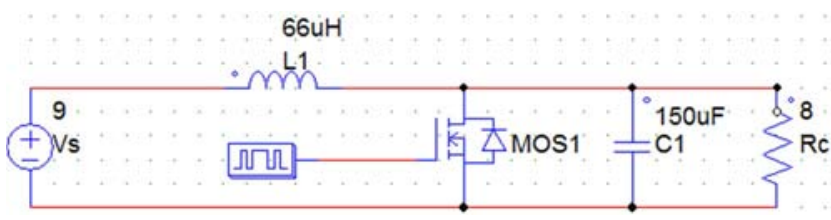

Figure 2. Boost converter.

The current in the coil must be permanent and the ripple of the voltage in the coil must be less than $1 \%$. An $8 \Omega$ resistive load is used to obtain a current capable of loading the supercapacitor bank. The duty cycle "D" is determined by the equation (1), which is defined in terms of the Vs (source voltage) and Vo (output voltage)

$$
D=1-\frac{V_{S}}{V_{O}}=\frac{9}{12}=.28
$$

A $25 \mathrm{kHz}$ working frequency is selected to switch on/off the switching device in a way that the coil operates at a higher range than that perceived by the human ear. The minimum inductance for permanent current is determined by equation (2)

$$
L_{\text {min }}=\frac{D(1-D)^{2} R}{2 f}=\frac{.28(1-.28)^{2} 8}{50000}=23.22 \mu \mathrm{H}
$$

To ensure that the system is working at permanent current, the coil value is increased by $25 \%$, therefore the coil value is $L=28.75 \mu \mathrm{H}$.

Now it is calculated the maximum and minimum coil currents

$$
\begin{gathered}
I_{L}=\frac{V_{S}}{(1-D)(1-D) R}=\frac{9}{(1-.28)^{2} 8}=2.17 \mathrm{~A} \\
\frac{\Delta_{i L}}{2}=\frac{V_{S} D T}{2 L}=\frac{(9)(.28)}{2\left(28.75 \times 10^{-6}\right)(25000)}=1.88 \mathrm{~A} \\
I_{\text {max }}=I_{L}+\frac{\Delta_{i L}}{2}=4.17 \mathrm{~A} \\
I_{\text {min }}=I_{L}-\frac{\Delta_{i L}}{2}=.41 \mathrm{~A}
\end{gathered}
$$

Finally, the ripple of the output voltage is obtained using the equation (7).

$$
C=\frac{D}{R f\left(\Delta V_{o} / V_{o}\right)}=\frac{.28}{8(25000)(0.01)}=150 \mu f
$$

\subsection{Supercapacitors Bank}

The simplest model for a supercapacitor incorporates the equivalent circuit of the Figure 3 . The equivalent series resistance (ESR) represents the conduction losses. Since the activated carbon sheets have a very high conductivity, this series resistance is very small in a range of $1-10 \mathrm{~m} \Omega$. The parallel equivalent resistance (EPR) represents leakage current losses in a range of 1-10 mA, whereby the equivalent resistance value is on the order of $100 \mathrm{k} \Omega,[13]-[16],[19]$, [20], [24]- [28].

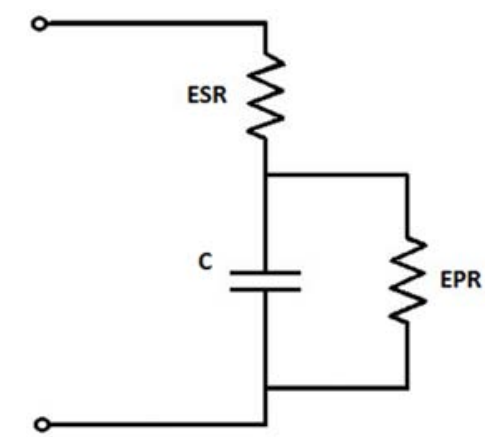

Figure 3. Supercapacitor Equivalent Circuit.

A supercapacitor can be considered as an $\mathrm{RC}$ circuit, so the charge or discharge cycle is similar to that of a conventional capacitor. Therefore, the load to constant voltage corresponds to the following expression

$$
v(t)=V_{0}\left(1-e^{-\frac{t}{\tau}}\right)
$$


where $\tau$ is the characteristic time constant, given by

$$
\tau=R_{E S R} C
$$

$\tau$ has a typical time constant value of about one second. A time constant reflects the required time to charge a capacitor at $63.2 \%$ full load or discharge at $36.8 \%$ of full load.

\subsection{Voltages Balancing Circuit}

Because the SC have a huge molecular surface which achieves their high capacities, the distance between anode and cathode is infinitesimal and therefore the internal voltages which can handle without insulation problems are small. This generates the reduction of the nominal and maximum voltages of each element, which are between $2.3 \mathrm{~V}$ and $2.7 \mathrm{~V}$ commonly. Considering these limitations, it is necessary to connect several SCs in a serial configuration to increase the operating voltage, however the voltage over a serial connection will not be equally distributed between the different SCs. If this effect is not compensated, a local overvoltage can appear in more than one supercapacitor. The balancing circuit shown in Figure 4 is considered as the active type and includes the use of a voltage divider, an operational amplifier, a negative feedback resistor and transistors, [1], [2], [4], [5], [18], [23].

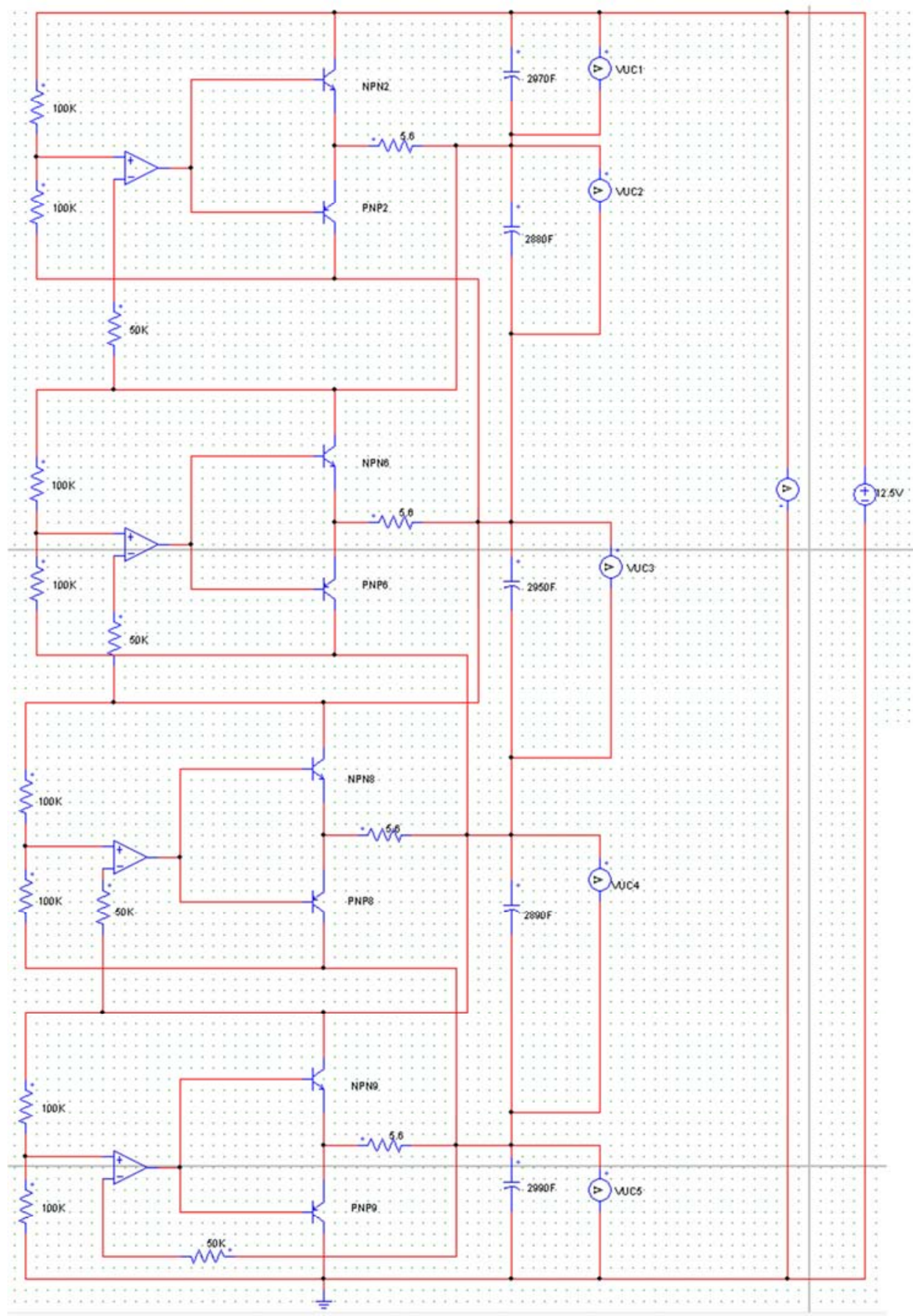

Figure 4. Schematic diagram of active swing circuit. 
The balancing topology is applied to balance the voltage of 5 supercapacitors set of $3000 \mathrm{~F}$ connected in series. The two transistors connected to the output of each amplifier npn and pnp provide a gain stage that is used to reduce the time in which the voltages are balanced in each connected supercapacitor, mainly for supercapacitors with capacities of $50 \mathrm{~F}$ to $3000 \mathrm{~F}$. The gain stage is configured to provide a current of $300 \mathrm{~mA}$ at the output of each amplifier. The resistors in the voltage divider are equal to equally divide the load voltage across the $\mathrm{SC}$, in this case $100 \mathrm{~K} \Omega$, the feedback resistance is about half the dividing resistors $(500 \mathrm{~K} \Omega)$ in such a way that this Resistance can cancel a polarized current input supplied to the operational amplifier, the current limiting resistance is $5.6 \Omega$. An advantage provided by this balancing circuit is that it allows a cascade connection to be able to balance the voltage of a considerable number of SC connected in series. Table 1 shows the initial voltage at which the SC are charged and the capacitance of each, [3].

Table 1. Initial voltage for each supercapacitor.

\begin{tabular}{lll}
\hline Nr. Supercapacitor & Initial Voltage & Capacitance \\
\hline C1(Supercapacitor 1) & $.006 \mathrm{~V}$ & $3000 \mathrm{~F}$ \\
C2(Supercapacitor 2) & $.0051 \mathrm{~V}$ & $3000 \mathrm{~F}$ \\
C3(Supercapacitor 3) & $.0095 \mathrm{~V}$ & $3000 \mathrm{~F}$ \\
C4(Supercapacitor 4) & $.0062 \mathrm{~V}$ & $3000 \mathrm{~F}$ \\
C5(Supercapacitor 5) & $.0072 \mathrm{~V}$ & $3000 \mathrm{~F}$ \\
\hline
\end{tabular}

\subsection{CAN Bus Network}

The nodes of the CAN bus network are integrated in the dsPIC30F4013. The CAN architecture contained in the PIC is able to communicate with other devices and the transceiver MCP2551. This module converts the voltage levels delivered by the dsPIC to the voltage levels required by the CAN bus network. Figure 5 shows the CAN network used [6] - [10].

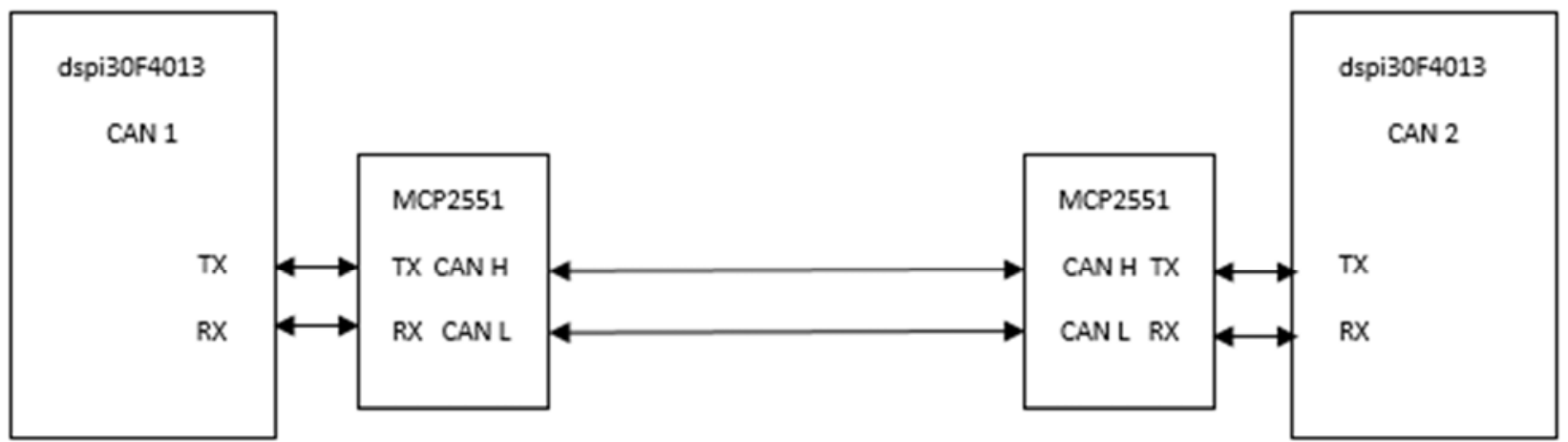

Figure 5. CAN network topology.

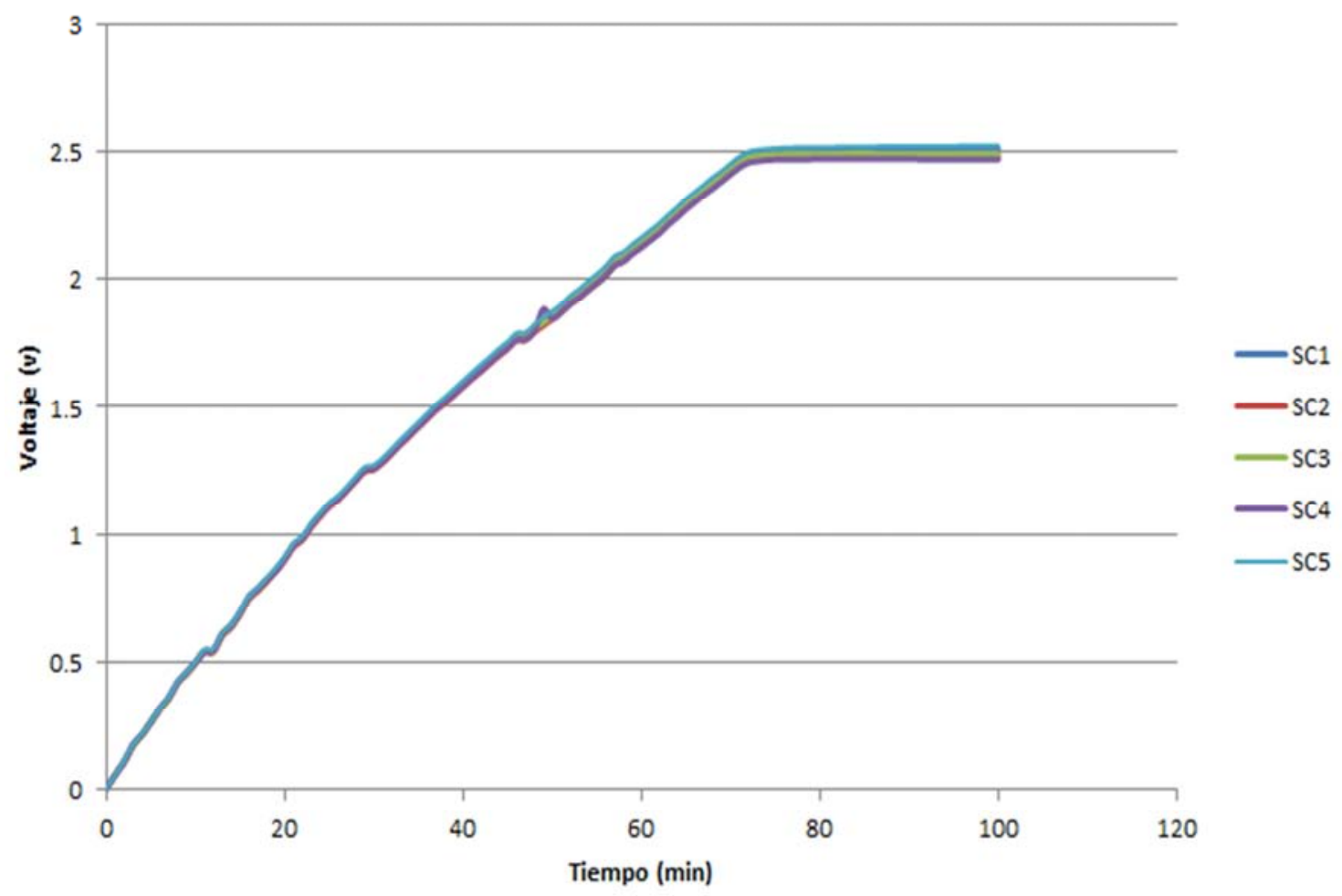

Figure 6. Experimental platform and rolling results. 


\section{Can Communication Matrix}

The design of the communication matrix for the CAN bus network is a requirement of the system. This matrix specifies the messages that will be transmitted through the bus. ID and DLC and signals carry the frames. Table 2 shows the information required in the matrix.

Table 2. CAN communication matrix.

\begin{tabular}{llllllllll}
\hline ID & TX & RX & DLC & SIGNAL & INITIAL BIT & SIGNAL BITS & MIN VALUE & MAX VALUE & INTERPRETATION \\
\hline 069 & CAN1 & CAN2 & 8 & voltage & 0 & 63 & 0 & 255 \\
073 & CAN1 & CAN2 & 4 & voltage & 0 & 15 & 0 & Voltage digital value \\
\hline
\end{tabular}

\section{Results}

Figure 6 shows the results obtained during the SCB loading. The voltage in each SC remained balanced from the beginning of charging stage until the maximum voltage of
$2.5 \mathrm{~V}$ in an interval time of 70 minutes.

Using an oscilloscope it was verified that the CAN frames were transmitted according to the communication matrix, the CAN frames and their decoding are shown in Figure 7. We can observe that both the ID, DLC and information are correct. This can proved after the decoding process in the oscilloscope.
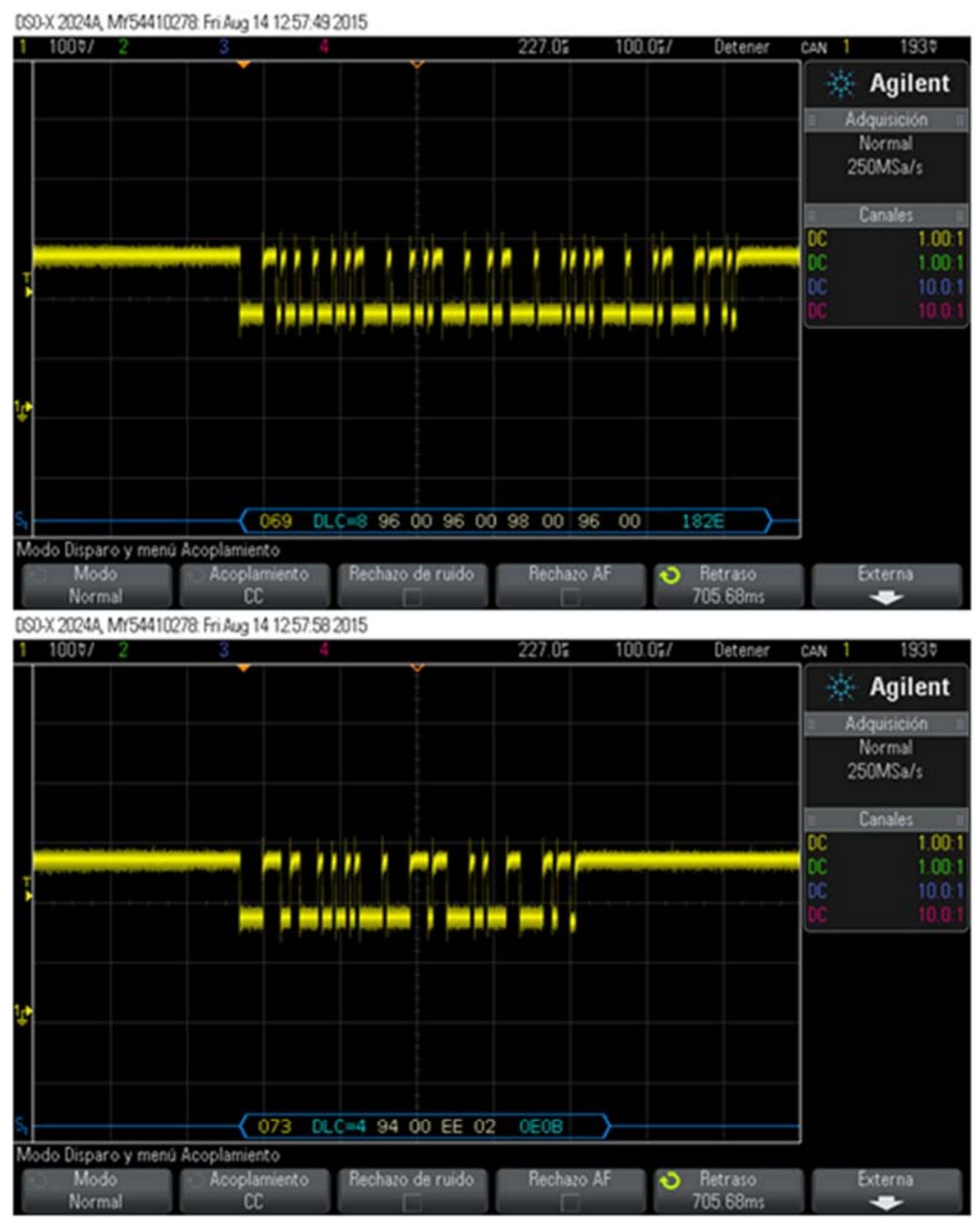

Figure 7. CAN frames and decoding. 
The experimental platform and the voltages of each SC can be seen in Figure 8.

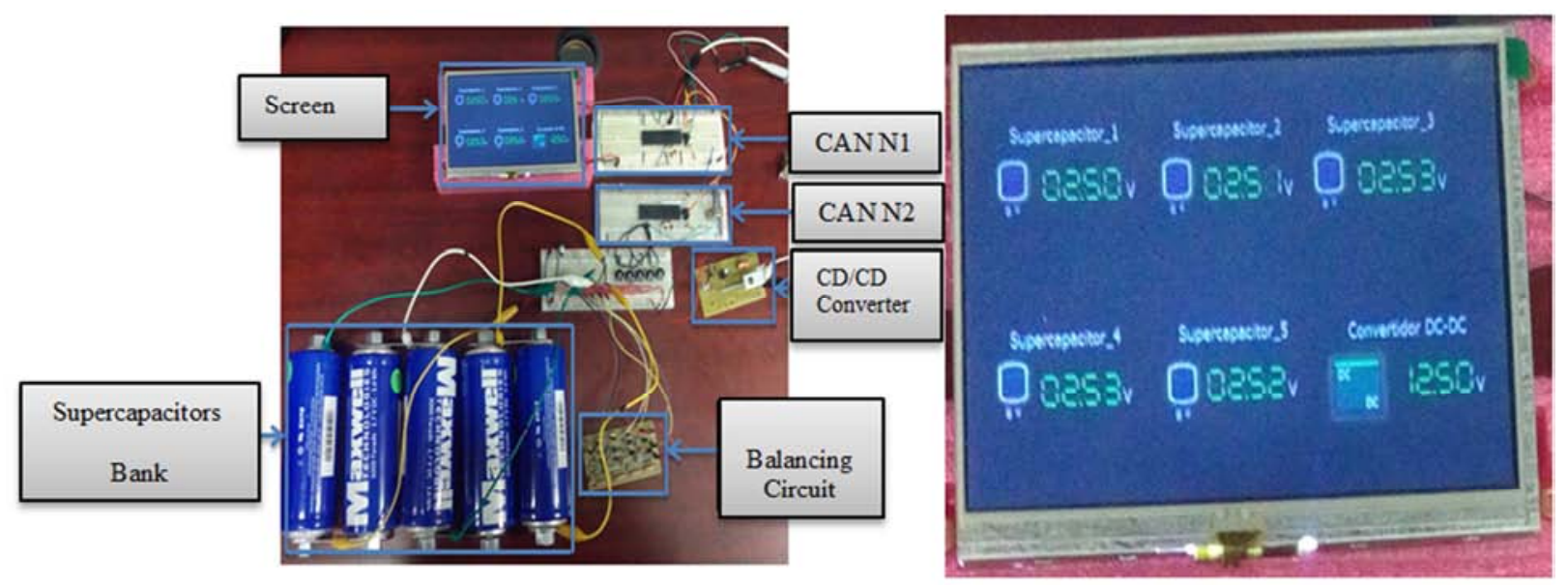

Figure 8. Experimental platform and results on the screen.

\section{Conclusions}

During the performed tests the system showed the expected operation. The power supplied by the DC/DC converter and the current needed to charge the SCB, did possible the transmission of the data through the CAN network as well as the interconnection with the graphical interface. The monitoring of the voltages of the SCB and DC/DC converter was correctly displayed on the screen, showing the ability of the CAN network to transmit large amounts of data without loss of them.

This work showed improvements by displaying other variables on the screen as current and displays an alert warning when there is an over voltage in some SC or some problem in the DC/DC converter. The developed system can also be extended to monitor a greater amount of SC depending on the required application through the same topology.

\section{References}

[1] Daniel W. Hart, "Electrónica de Potencia", Prentice Hall Hispanoamericana, S. A, Primera Edición, Pag. 226 - 279, 2001.

[2] Muhammad H. Rsahid, "Electrónica de Potencia, Circuitos dispositivos y aplicaciones", Prentice Hall Hispanoamericana, S. A, Segunda Edición, Pag. 226 - 279, 1993.

[3] N Maxwell, Ultracapacitor product guide, Maxwell Technologies Inc, San Diego CA, December 2014.

[4] http:/electricitystorage.org/tech/technologies_comparisons_lif eefficiency.htm (Accessed on: January 7, 2015).

[5] Thrap, Guy C. "Charge balancing circuit." U.S. Patent No. 6,806,686, 19 Oct. 2004

[6] Robert Bosch GmbH, "CAN Specification Version 2.0", The Bosch IC Design Centre, Reutingen, DE, 1991.

[7] Emani, K. C., Kam, K. and Zawodniok, M., 'Improvement of CAN bus performance by using error correction codes', 2007
IEEE.

[8] 'Using CAN Bus Serial Communications in Space Flight Applications', Intersil white paper, http://www.intersil.com (2016).

[9] 'ISL7202xSEHEVAL1Z Evaluation Board User Guide', Intersil document UG051, http://www.intersil.com (2016).

[10] B. Ling, F. Peng, and A. Li, "The Car Body Control Bus Design Based on CAN/LIN Bus," in Computational and Information Sciences (ICCIS), 2011 International Conference on, 2011, pp. 885-888.

[11] Kirsch D. (1996) The Electric Car and the Burden of History: Studies in Automotive System Rivalry in the United Stares, 1996.

[12] American Petroleum institute (API), Alcohols and Ethers, Publication No. 4261, $2^{\text {nd }}$ ed. (Washington, DC, July 1988), Table B-1, 1988.

[13] Massot Campos Miguel, "Frenado Regenerativo en vehículos eléctricos mediante supercondensadores”, Revista Automátia e Instrumentación, n. 43, p. 59 - 64, 2011.

[14] Mera, Isaac Gil. "Diseño de un Sistema de almacenamiento de energía híbrido basado en baterías y supercondensadores para su integración en microredes eléctricas". Tesis. Escuela Superior de Ingenieros, Universidad de evilla, 2011.

[15] Baeza Marcos, "Electric Vehicle", http://blogs.elpais.com/[Research:thursday march 03, 2014], 2011.

[16] García Gallegos, J. Carlos, Qué son los supercondensadores?, http://papelperiodico.com/[Research:wednesday, march 02, 2014], 2013.

[17] Mesa Montoya, Carlos Andrés, "Introducción a los Sistemas de Comunicación del vehículo",

http://mgiportal.sena.edu.com/[Research:wednesday, march 10, 2014], 2008.

[18] Yoong M. K., Gan Y. H., Gan G. D., Leong C. K., Phuan Z. Y., Cheah B. K., \& Chew K. W. (2010, November). "Studies of regenerative braking in electric vehicles, in sustainable utilization and development in Engineering and Technology", IEEE conference on (pp. 40 - 45), 2010. 
[19] Shi L., \& Crow M. L. Comparison of Ultracapacitor electric Circuit Models. In Power and Energy Society General Meeting-Conversion and Delivery of Electrical Energy in the $21^{\text {st }}$ Century. IEEE (pp. 1-6), 2008.

[20] Paul K., Christian M., Pascal V., Guy C., Gerard R., \& Younes Z. "Constant Power Cycling for Accelerated ageing of supercapacitors. In Power Elecronics and Applications", 2009. EPE'09. $13^{\text {th }}$ European Conference on (pp. 1-10). IEEE, 2009.

[21] Barrade P. "Series Connection of Supercapacitors: Comparative Study of Solutions for the Active Equalization of the Voltages". Proceedings of $7^{\text {th }}$ international Conference on Modeling and Simulation of Electric Machines, Converters and Systems, IEEE, 2002.

[22] Qu Y., Zhu J., Hu J., \& Holliday B. "Overview of supercapacitor cell voltage balancing methods for an electric vehicle". In ECCE Asia Downunder (ECCE Asia), IEEE (pp. 810 - 814). IEEE, 2013.

[23] Ren-gui L., Lei P., Rui M., Jun-lei W., \& Chun-bo Z. "EV energy storage monitoring system based on distributed data acquisition". In Vehicle Power and Propulsion Conference, VPPC'09. IEEE (pp. 1386-1389). IEEE, 2009.
[24] Joel Shindall "The Charge of the Ultracapacitors Nanotechnology takes energy storage beyond batteries", IEEE Spectrum, November 2007.

[25] Glenn Zorpette. Super Charged. "A tiny south Korean company is out make capacitors powerful enough to propel the next generation of hybrit-electric cars". IEEE Spectrum, January 2005 .

[26] Tonzhen Wei, "Deterioration Diagnosis of Ultracapacitor for Power Electronics Applications", IEEE, Sydney Australia, Tech, 2008.

[27] Junseok Song, "A Rapid Charging Station with an Ultracapacitor Energy Storage System for plug - in Electrical vehicles. Department of Electrical and Computer Engineering”, The University of Texas at Austin, USA, 2011.

[28] Su C. Q. \& Zhang D. Q. "Computer simulation Study on Ultracapacitor for Electric Vehicle. In Intelligent Computin and Intelligent Systems", ICIS 2009. IEEE International Conference on (Vol. 1, pp. 199-203). IEEE, 2009. 